\title{
Fatores e erros humanos na inspeção de segurança da aviação civil brasileira
}

Human factors and errors in the brazilian civil aviation security inspection Los factores y errores humanos en la inspección de seguridad de la aviación civil brasileña

\author{
Michelle Salgado Ferreira ARCÚRIO ${ }^{1, a}$ \\ José Augusto Abreu Sá FORTESa \\ Talita ARMBORST ${ }^{\mathrm{b}}$ \\ Universidade de Brasília, Brasília, DF, Brasila ${ }^{a}$, Agência Nacional de Aviação Civil, Brasília, DF, Brasil ${ }^{b}$
}

ResumO A área de security, e especificamente de security no canal de inspeção de segurança da aviação civil brasileira, apresenta carência de estudos quanto à identificação, à quantificação, à causa e ao impacto de fatores e erros humanos. Este estudo teve o objetivo de identificar os fatores e erros humanos envolvidos no processo de inspeção de segurança da aviação civil brasileira. Empregando-se a teoria do sistema geral de modelagem do erro - GEMS “Generic Error-Modelling System”- e os quatro eixos temáticos sobre fatores humanos preconizados pela Organização de Aviação Civil Internacional (OACI), elaborou-se o instrumento da pesquisa constituído por 60 questões. A amostra foi composta por 602 (seiscentos e dois) profissionais AVSEC (segurança da aviação civil contra atos de interferência ilícita) que laboram no canal de inspeção, distribuídos em 18 (dezoito) aeroportos brasileiros. Os resultados foram retratados por meio de estatística descritiva e Análise de Componentes Principais (ACP). Os principais pontos da etapa descritiva fazem referência ao tempo de serviço majoritário no canal de inspeção, ao grau de escolaridade e ao de rendimento mensal bruto. Após as etapas da ACP, 46 itens do questionário foram categorizados em 7 (sete) componentes principais, os quais representaram 42,04\% da proporção total da variância explicada dos dados, isto é, dos erros e fatores humanos pesquisados. Concluiu-se, a partir da ACP, que há incidência de fatores e erros humanos no processo de inspeção de segurança, cujos percentuais são retratados neste artigo.

Palavras-chave:

Fatores humanos; segurança da aviação civil; canal de inspeção.

\section{Abstract}

This study aimed at identifying human factors and errors that may exist in the Brazilian civil aviation security inspection process. Employing the theory of the Generic Error Modeling System (GEMS) and the four themes about human factors recommended by the International Civil Aviation Organization ICAO, the research instrument was formulated, being composed of 60 questions. The sample was composed of six hundred and two (602) AVSEC professionals (civil aviation security against acts of unlawful interference) who work in security check points, covering eighteen (18) Brazilian airports. The results were presented using descriptive statistics and Principal Components Analysis - PCA. The main points of the descriptive stage related to the preponderant length of service, level of education, and monthly income. After the PCA steps, 46 questionnaire items were categorized into seven (7) principal components, which represented $42.04 \%$ of the total variance being explained by the data. It was concluded from the PCA that there is incidence of human factors and errors in the security inspection process, whose percentages are described in this article.

Keywords:

Human factors; civil aviation security; security check point. 
al respecto de errores y factores humanos. Este estudio tuvo como objetivo identificar los factores y los errores humanos que intervienen en el proceso de inspección de seguridad de la aviación civil brasileña. Al emplearse la teoría del sistema de modelación del error -GEMS "Generic Error - Modelling System- y de las cuatro áreas temáticas de los factores humanos recomendados por la Organización de Aviación Civil Internacional (OACI), se elaboró un instrumento de investigación constituido de 60 preguntas. La muestra consistió en 602 (seiscientos dos) profesionales AVSEC (seguridad de la aviación civil contra actos de interferencia ilícita), que trabajan en el canal de inspección de seguridad, repartidos en dieciocho (18) aeropuertos. Los resultados fueron retratados a través de estadística descriptiva y Análisis de Componentes Principales (ACP). Los puntos principales de la etapa descriptiva se refieren al tiempo de servicio en el canal de la inspección, el nivel de escolaridad y el ingreso bruto mensual. Tras los pasos de la ACP, 46 ítems del cuestionario fueron clasificados en 7 (siete) componentes principales, que representaron el $42.04 \%$ de la proporción total de varianza explicada de los datos. Se concluyó, a partir de la ACP, que hay incidencia de factores y errores humanos en el proceso de inspección de seguridad, cuyos porcentajes son retratados en este artículo.

Palabras-clave:

Factores humanos; seguridad de la aviación civil; canal de inspección.

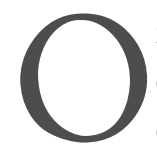

mercado de aviação civil brasileira experimenta um momento histórico sem precedentes, uma vez que o setor aéreo assumiu um papel de destaque na economia do país, dado o aumento no fluxo de passageiros e cargas (Tadeu, 2010). Atualmente, o mercado aéreo conta com a diversificação de tarifas, fato que estimula a expansão da demanda e proporciona aos usuários melhor qualidade dos serviços ofertados. De acordo com o relatório de tráfego aéreo mundial de 2012, emitido pelo Conselho Internacional de Aeroportos (ACI), a aviação brasileira ocupou a $5^{\text {a }}$ colocação, em termos de passageiros transportados, incluindo voos domésticos e internacionais, sendo o primeiro lugar ocupado pelos Estados Unidos, seguido pela China, Reino Unido e Alemanha (Airports Council International, 2012).

É importante observar que a evolução do transporte aéreo e o relacionamento entre nações devem ter como base fundamental os princípios gerais que proporcionem, aos usuários, critérios de segurança, regularidade e eficiência, conforme o art. 25 do Código Brasileiro de Aeronáutica, Lei 7.565/1986. Isso porque, em qualquer país, a fiabilidade do funcionamento do sistema aéreo é fator imprescindível para o seu crescimento.

No entanto, o aumento no volume do tráfego aéreo em nível mundial nos últimos anos trouxe maior evidência à aviação civil, sendo essa uma das razões de o setor ser alvo de ameaça de atos ilícitos, como o atentado terrorista ocorrido em 11 de setembro de 2001 nos Estados Unidos. Entre as possíveis razões que tornam a aviação objeto de atração para ações terroristas estão: ampla publicidade mundial; poucos agressores controlam muitos passageiros; presença de pessoas de diversas nacionalidades; possibilidade de fuga utilizando a própria aeronave; valor e vulnerabilidade dos aviões; transporte aéreo de valores; motivações relacionadas ao crime comum; crime organizado; e razões socioeconômicas (Amores \& Fernández, 2012). Com a ocorrência do atentado de 2001,outrora impensável, a sociedade mundial se conscientizou sobre a necessidade de adoção de medidas que evitassem situações de vulnerabilidade ao sistema de aviação civil ou de potencial perigo para passageiros, tripulações e para os próprios aviões, além da infraestrutura aeroportuária e do público em terra.

Portanto, a segurança nacional perpassa por procedimentos de segurança denominados, no âmbito do sistema de aviação civil, de aviation security ou simplesmente security, ou, ainda, AVSEC (segurança da aviação civil contra atos de interferência ilícita). Esse conceito está estabelecido no inciso XI do art. $3^{\circ}$ do Decreto n 7.168 de 5 de maio de 2010,que também lista o que é considerado ato de interferência ilícita: (a) apoderamento ilícito de aeronave em voo; (b) apoderamento ilícito de aeronave no solo;(c) manutenção de refém a bordo de aeronaves ou nos aeródromos; (d) invasão de aeronave, de aeroporto ou das dependências de instalação aeronáutica; (e) introdução de arma, artefato ou material perigoso, com intenções criminosas, a bordo de aeronave ou em um aeroporto; (f) comunicação de informação falsa que coloque em risco a segurança de aeronave em voo ou no solo, dos passageiros, tripulação, pessoal em terra ou público em geral, no aeroporto ou nas dependências de instalação de navegação aérea; e (g) ataque a aeronaves utilizando sistema antiaéreo portátil.

Assim, os fatores e erros humanos, quando combinados com rupturas nas camadas de defesa do sistema de segurança, criam uma trajetória de oportunidades para que sejam cometidos atos de interferência ilícita e ensejem o aumento de vulnerabilidades. Esses fatores e erros podem desencadear riscos nos níveis mínimos aceitáveis de segurança, conforme a teoria de queijo suíço de Reason (1990). Essa teoria reflete que é pequena a 
probabilidade de que essa trajetória encontre lacunas em todas as defesas ao mesmo tempo, pois o alinhamento das lacunas em todas as camadas de defesa ou em todo o percurso é uma situação atípica.

Dessa forma, o objetivo principal desta pesquisa foi identificar os erros e fatores humanos que podem existir no processo de inspeção de segurança da aviação civil. Os objetivos específicos deste estudo se referiram a: (a) determinar se existem fatores e erros humanos predominantes no processo de inspeção de segurança; (b) avaliar o impacto dos fatores e erros humanos no processo de inspeção de segurança da aviação civil; e (c) definir as possíveis causas dos fatores e erros humanos no canal de inspeção de segurança da aviação civil.

Ante os objetivos propostos, vale destacar que a localização do canal de inspeção nos aeroportos é estratégica, pois além de ser um dos componentes da defesa em profundidade, faz a mediação entre a área de circulação do público em geral presente no aeroporto e a área restrita de segurança (ARS). Portanto, é uma medida de segurança que garante a separação, no tempo e no espaço, dos fluxos de embarque e desembarque de pessoas inspecionadas e não inspecionadas.

O canal de inspeção da aviação civil é um local que concentra equipamentos de segurança e profissionais AVSEC capacitados que interagem de forma conjunta, harmônica e integrada para evitar que sejam introduzidos, em área restrita de segurança e em aeronaves, itens que possam ser utilizados para cometer atos de interferência ilícita.

No canal de inspeção (Figura 1), atuam profissionais AVSEC denominados agentes de proteção da aviação civil (APACs). A finalidade do trabalho dos APACs é prevenir que armas, explosivos, artefatos e agentes químicos, biológicos, radioativos, nucleares ou substâncias e materiais proibidos sejam introduzidos sem autorização às ARSs, ou a bordo de aeronave.

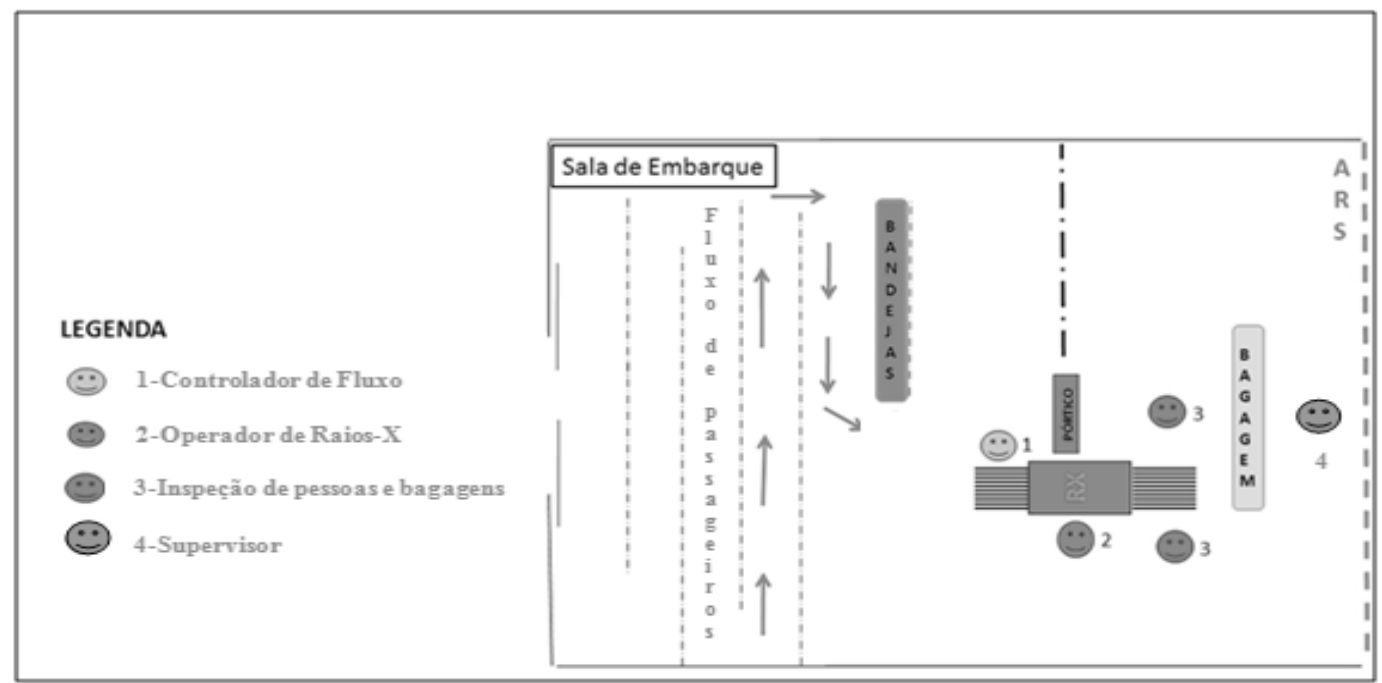

FIGURA 1. Representação esquemática do canal de inspeção de aeroportos brasileiros. Fonte: Estudo Canais de Inspeção (ANAC/ INFRAERO, 2014, adaptado pelo autor).

Sobre as especificidades globais de cada uma das funções a serem desempenhadas, a partir da análise do contexto operacional do canal de inspeção de segurança, é possível concluir que: (a) controlador de fluxo: tem a função de organizar e controlar o fluxo de passageiros a serem inspecionados, solicitando que aguardem a vez na posição demarcada; (b) inspeção manual de passageiros e bagagens de mão: é responsável pela condução das inspeções realizadas junto aos passageiros e bagagens de mão; (c) operador de equipamento de raios-X: monitora as bagagens e objetos junto ao equipamento, com o objetivo de detectar itens proibidos e/ou artefatos explosivos ou materiais de acesso controlado; e (d) supervisor: supervisiona as atividades realizadas pelos agentes de proteção durante o período de funcionamento do canal de inspeção.

Considerando-se as limitações tecnológicas imperantes no sistema de aviação civil, de modo que não é possível utilizar apenas recursos tecnológicos em detrimento do trabalhador, o estudo acerca dos fatores e erros humanos na segurança se constitui como uma reação a essa conjuntura, pois são os profissionais atuantes nesse sistema que tomam as decisões críticas em prol da segurança contra ilícitos.

Conforme assevera Reason (1990), a partir do conhecimento de métodos efetivos de predição, à luz da psicologia, por meio da compreensão dos processos cognitivos, torna-se viável explicar as variedades mais previsíveis da falibilidade humana e, com isso, reduzir sua incidência. Por definição, o erro é um termo "genérico 
utilizado para englobar todas as ocasiões em que uma sequência planejada de atividades mentais ou físicas não consegue alcançar um resultado desejado e quando esse fracasso não pode ser atribuído ao acaso" (Reason, 2009, p. 35).

Na discussão sobre a definição de erro humano, Senders e Moray (1991, citado por Strauch, 2002) afirmam que o erro é algo que foi feito sem a intenção de quem o praticou. É algo não desejável sob o ponto de vista das normas ou de observadores externos e que desvia a atividade laboral ou o sistema de seus limites aceitáveis. $\mathrm{Na}$ concepção de Woods, Johannesen, Cook e Sarter (1994, citado por Strauch, 2002), o erro é uma variação específica do desempenho humano. Além disso, no momento em que o profissional incorre em tal variação ou quando essa é omitida, não resta dúvida de que foi objeto de desaprovação por quem a cometeu.

Todavia, Abrahão, Sznelwar, Silvino, Sarmet e Pinho (2009) apresentam uma característica diferenciadora quando elucidam que a concepção de erro humano pressupõe um modo certo para agir e, portanto, deveria ser revisto. Assim, o erro deveria ser considerado "o insucesso de uma ação que é influenciada diretamente pelo ambiente" (pp. 63-64). Com base nesse entendimento, o insucesso não deve ser atribuído ao trabalhador, mas à configuração do ambiente de trabalho.

Hollnagel (1993, citado por Strauch, 2002) também questiona a terminologia erro humano, pois a avalia como demasiadamente simplista e que o termo açôes errôneas deveria substituí-la. O autor entende que ações errôneas são atos que não produzem o resultado esperado e que, portanto, levam a uma consequência indesejada. Ele argumenta que não se deve fazer julgamentos sobre a causa do evento. A ação errônea, ao contrário de erro, não implica qualquer julgamento e representa o contexto em que ocorre a ação. Em uma visão similar, Strauch (2002) entende que os erros refletem uma influência interna ou externa no desempenho humano, uma vez que os profissionais desejam trabalhar corretamente, mas não conseguem devido às próprias características do sistema.

Reason (2009) afirma que a definição ou classificação do erro deve começar pela análise da intenção do comportamento. Não se pode falar de violação sem intenção. À intenção estão incorporados dois elementos: o resultado final que se pretende alcançar e os meios que serão utilizados para alcançar tal resultado. Assim, a palavra erro só pode ser aplicada para ações planejadas que não alcançaram seus objetivos, sem a intervenção de casualidades ou imprevistos.

A fim de delimitar os principais erros humanos associados à resolução de problemas, Reason (2009), base principal do construto teórico desta pesquisa, propôs um quadro esquemático, representado pela Tabela 1 baseado em três modalidades de erro humano: habilidades (deslizes e lapsos), regras e conhecimentos (equívocos).

TABELA 1. Resumo das três modalidades do erro humano

\begin{tabular}{lc}
\hline & Rendimento baseado em habilidades \\
\hline Falta de atenção & Excesso de atenção \\
Deslizes de dupla captação & Omissões \\
Omissões por interrupção & Repetições \\
Intencionalidade reduzida & Inversões \\
Percepção confusa & \\
Erros provocados por interferências &
\end{tabular}

Rendimento baseado em regras

Aplicação errônea de regras "boas"

Primeiras exceções

Sinais, contrassinais e ausência de sinais

Sobrecarga de informação

Força da regra

Regras gerais

Redundância

Rigidez
Aplicação inadequada de regras

Dificuldades na codificação

Deficiências na ação

Regras inadequadas

Regras desajustadas

Regras desaconselháveis 


\section{Rendimento baseado em conhecimentos}

\section{Seletividade}

Limitações do espaço de trabalho

Olhos que não veem, coração que não sente

Predisposição para confirmação

Excesso de confiança

llusão da verificação

Correlação ilusória

Efeito de halo

Problemas com a causalidade
Problemas com a complexidade

Atrasos na retroalimentação

Atenção insuficiente ao processo histórico

Comportamento de escape

Atenção prolongada em um único tema

Tendo em vista a variedade de erros humanos que compõem cada uma das modalidades propostas por Reason (2009) e com o objetivo de facilitar sua compreensão, apresenta-se a seguir uma descrição global de cada uma delas e um exemplo correspondente, com base nas atividades realizadas no canal de inspeção de segurança: (a) rendimento baseado em habilidades: tem como característica principal identificar os erros humanos decorrentes do excesso ou da falta de atenção e suas diferentes formas de aparição no ambiente de trabalho. Exemplo de erro humano relacionado às "primeiras exceções": não cumprir todos os procedimentos AVSEC quando se trata de autoridades; (b) rendimento baseado em regras: para executar uma tarefa, a cognição humana busca compatibilizar as regras existentes e a situação de trabalho para fazer predições e construir uma linha de ação por meio de associação. Nesse processo de ação, surge a aplicação errônea de regras "boas" e as falhas decorrentes da aplicação inadequada de regras. Exemplo de erro humano relacionado à "força da regra”: não aplicar todos os procedimentos de segurança no canal de inspeção; e (c) rendimento baseado em conhecimentos: no processo de resolução de problemas, os erros são decorrentes de aspectos básicos - a limitação da racionalidade humana ou de um modelo incompleto ou inexato do espaço do problema. Exemplo de erro humano relacionado à "Olhos que não veem, coração que não sente": colocar-se no lugar do passageiro e simplificar o processo de inspeção de segurança AVSEC.

Para complementar o processo de modelagem preconizado por Reason (2009) e atribuir um caráter técnico ao assunto, também foram abordados quatro eixos temáticos relacionados aos fatores humanos difundidos pelo DOC 9808 (Organización de Aviación Civil Internacional [OACI], 2002): operadores, tecnologia, entorno operacional e cultura organizacional e certificação, conforme a Figura 2.

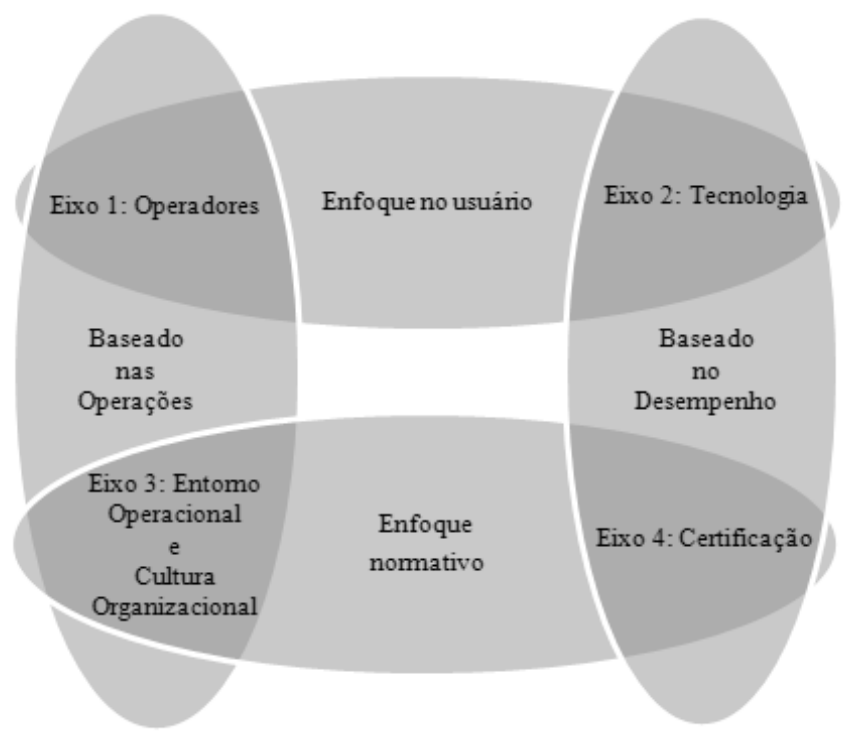

FIGURA 2. Representação esquemática dos aspectos relacionados aos fatores humanos. Fonte: DOC 9808 (OACl, 2002, adaptação e tradução nossa). 
Para melhor compreender os elementos apresentados e a inter-relação dos aspectos atinentes aos fatores humanos representados, cumpre ressaltar que o trabalho dos operadores (eixo 1), isto é, dos profissionais AVSEC, é realizado em um determinado entorno operacional (eixo 3), que exige alto nível de precisão, o qual é dotado de cultura organizacional (eixo 3).Segundo o DOC 9683 (OACI, 1998), a cultura dá forma ao comportamento e estrutura a percepção de mundo de um indivíduo, por isso sua relevância para o estudo dos fatores humanos e para a AVSEC. Nessa direção, a cultura se constitui como uma programação mental coletiva que distingue um grupo de outro, predispõe determinadas atitudes e influencia o comportamento dos indivíduos.

O trabalho realizado pelos profissionais AVSEC é amparado com frequência pelo emprego de tecnologias (eixo 2) para a implementação das medidas de segurança da aviação civil contra ilícitos, com o intuito de elevar sua eficácia e precisão. Por isso, possui enfoque nos usuários do transporte aéreo, visando à manutenção de sua integridade e segurança. O quarto e último eixo abordado no DOC 9808 (OACI, 2002) é constituído por elementos relativos à certificação, tanto de pessoal, quanto das tecnologias utilizadas e das organizações.

Conforme preconizado no DOC 9808 (OACI, 2002), é fundamental a elaboração e a atualização das normas concernentes à certificação de pessoal (eixo 4) que considere os princípios relativos à incidência e à mitigação de fatores humanos, os quais ocorrem no entorno operacional (eixo 3) e são aprendidos e perpetuados por meio da cultura organizacional (eixo 3). Portanto, a efetividade do processo de inspeção em segurança depende do enfoque normativo.

\section{MÉTODO}

Com o objetivo de elaborar amostragem do universo de APACs certificados pela Agência Nacional de Aviação Civil (ANAC), foi utilizada a amostragem aleatória simples (AAS), sem reposição. Além da AAS, foi utilizado o critério de amostragem por cotas, considerada quase aleatória, na qual se aplica o questionário a um número predefinido de pessoas, com vistas a obter uma amostra semelhante à população (número de APACs e aeroportos), conforme Bolfarine e Bussab (2000). O detalhamento do quantitativo de participantes na pesquisa foi representado na coluna denominada "No de Pesquisas (n)" da Tabela 2. Os dados foram submetidos a estatísticas descritivas e à análise de componentes principais (ACP), sendo esta aplicável para reduzir a dimensão dos dados. 


\begin{tabular}{|c|c|c|c|c|c|}
\hline \multirow[b]{2}{*}{$\begin{array}{l}\text { Fator de viabilidade } \\
\text { da pesquisa }\end{array}$} & \multirow[b]{2}{*}{ Tipo de coleta } & \multirow[b]{2}{*}{ Aeroporto pesquisado } & \multirow{2}{*}{$\begin{array}{c}\text { População } \\
\begin{array}{c}\text { Participação do } \\
\text { aeroporto }^{(4)}\end{array}\end{array}$} & \multicolumn{2}{|c|}{$\begin{array}{c}\text { Quantitativo estabelecido para a } \\
\text { pesquisa }\end{array}$} \\
\hline & & & & $\begin{array}{c}\mathrm{N}^{\circ} \text { de } \\
\text { pesquisas } \\
(n)\end{array}$ & $\begin{array}{l}\text { Participação do } \\
\text { aeroporto(5) }^{(5)}\end{array}$ \\
\hline \multirow{11}{*}{$\begin{array}{l}\text { Selecionados previa- } \\
\text { mente na amostra }\end{array}$} & $\begin{array}{l}\text { Realizada direta- } \\
\text { mente pelo pesqui- } \\
\text { sador }\end{array}$ & Brasília (DF) & $6,5 \%$ & 55 & $9,5 \%$ \\
\hline & \multirow{10}{*}{$\begin{array}{l}\text { Servidores do } \\
\text { NURAC }\end{array}$} & Galeão (RJ) & $9,7 \%$ & 81 & $13,9 \%$ \\
\hline & & Porto Alegre (RS) & $5,7 \%$ & 48 & $8,3 \%$ \\
\hline & & Campinas (SP) & $4,5 \%$ & 38 & $6,5 \%$ \\
\hline & & Recife (PE) & $3,5 \%$ & 29 & $5,0 \%$ \\
\hline & & Salvador (BA) & $3,4 \%$ & 29 & $5,0 \%$ \\
\hline & & Congonhas (SP) & $2,3 \%$ & 19 & $3,3 \%$ \\
\hline & & Manaus (AM) & $2,1 \%$ & 18 & $3,1 \%$ \\
\hline & & Confins (MG)(1) & $2,0 \%$ & 17 & $2,9 \%$ \\
\hline & & Santos Dumont(RJ) & $2,4 \%$ & 17 & $2,9 \%$ \\
\hline & & Belém (PA) & $1,1 \%$ & 9 & $1,5 \%$ \\
\hline \multirow{7}{*}{$\begin{array}{l}\text { Não selecionados pre- } \\
\text { viamente na amostra }\end{array}$} & \multirow{3}{*}{$\begin{array}{l}\text { Portaria ANAC } \\
n^{\circ} 01 / 2013\end{array}$} & Guarulhos (SP) & $20,0 \%$ & 167 & $28,7 \%$ \\
\hline & & Curitiba (PR) & $3,8 \%$ & 33 & $5,7 \%$ \\
\hline & & Marabá $(P A)^{(2)}$ & $0,1 \%$ & 4 & $0,7 \%$ \\
\hline & \multirow{4}{*}{ Outros Motivos } & Pampulha (BH) & $0,5 \%$ & 7 & $1,2 \%$ \\
\hline & & Rio Branco (AC) & (3) & 6 & $1,0 \%$ \\
\hline & & Santarém (PA) & $0,02 \%$ & 3 & $0,5 \%$ \\
\hline & & Navegantes (SC) & $1,0 \%$ & 1 & $0,2 \%$ \\
\hline
\end{tabular}

Nota. (1) Parcialmente; (2) Foi pesquisada toda a população do aeroporto; (3) Neste caso, o aeroporto não constava no banco populacional de dados; (4) Abrange todos os aeroportos brasileiros que tenham profissionais AVSEC vinculados a eles; (5) Percentual que um determinado aeroporto representa para a pesquisa, de acordo com a amostra de aeroportos selecionados. Fonte: Banco de dados AVSEC Habilitados (ANAC, 2013).

\section{Participantes}

Os sujeitos desta pesquisa foram 602 APACs que atuam nos canais de inspeção de segurança de 18 aeroportos brasileiros, especificadamente, formados no curso AVSEC para operador especializado em raios-X e/ou no curso de Supervisão em Segurança da Aviação Civil, com, no mínimo, um mês de experiência laboral em canais de inspeção de segurança.

\section{Instrumento}

A fim de identificar os fatores e erros humanos no processo de inspeção de segurança, foi aplicado um questionário de auto-observação aos sujeitos da pesquisa, no qual foram apresentadas descrições ou exemplos de possibilidades de fatores e erros humanos, e lhes foi solicitado que qualificassem a frequência, o nível de intensidade ou de concordância das assertivas apresentadas.

O instrumento da pesquisa foi submetido à validação técnica por uma equipe de três servidores da ANAC, da Gerência Técnica para Segurança da Aviação Civil contra Atos de Interferência Ilícita - GTSG. O objetivo da validação do instrumento da pesquisa foi elevar o grau de confiabilidade e assegurar a compreensão das assertivas. Por essa razão, esse processo de validação dista de se constituir como um objetivo desta pesquisa.

\section{Procedimento de coleta de dados e cuidados éticos}

A aplicação dos questionários foi realizada durante a realização dos exames de certificação de profissionais AVSEC no curso de Operador Especializado em Raios-X, com a devida anuência da ANAC, durante os anos 
de 2013 e 2014. Esse certame ocorre, anualmente, em função do curso AVSEC realizado pelo profissional de segurança. Nos casos em que não foi possível a aplicação do questionário nos exames de certificação de profissionais AVSEC, a pesquisa foi realizada sob os mesmos critérios, por servidores da ANAC lotados nos Núcleos Regionais de Aviação Civil (NURAC).

A fim de assegurar eticidade à pesquisa e o sigilo à pessoa-participante ou de alguma informação capaz de identificá-la, a saber, os profissionais AVSEC, o questionário da pesquisa não consignou a identificação do respondente.

\section{Procedimentos de análise de dados}

As respostas aos questionários foram registradas em banco de dados do SPSS (Statistical Package of Social Science). Os resultados apresentam-se do seguinte modo: (a) análise descritiva dos dados preliminares da pesquisa, que incluem os principais dados socioeconômicos sobre a amostra pesquisada, bem como das informações técnicas constantes nas questões não abarcadas nos componentes principais estabelecidos; (b) avaliação estatística dos dados referente à $\mathrm{ACP}$ por meio da síntese dos resultados, com vistas a possibilitar a avaliação e comportamento das variáveis de forma conjunta, baseado no critério Varimax, cujo objetivo é maximizar a variação entre os pesos de cada componente principal; e (c) figura explicativa dos fatores humanos ou erros incidentes no canal de inspeção inseridos no contexto da análise estatística.

\section{RESULTADOS}

\section{Estatística descritiva}

A partir da coleta dos dados preliminares, empregando-se 11 questões socioeconômicas, foi possível traçar o perfil e as características da população-alvo, além de suas condições gerais de trabalho. De forma geral, a amostra não é homogênea. Houve variação na idade e o gênero predominante foi o feminino, com representatividade de 66\%. No que tange à distribuição etária, notou-se maior concentração de profissionais, 36\%, com idade entre 30 a 39 anos em todos os aeroportos pesquisados. Já $20 \%$ dos respondentes encontram-se na faixa etária de 25 a 29 anos. Em terceiro lugar estão os profissionais com idade entre 40 a 49 anos, representando $18 \%$ da população pesquisada. O menor índice dessa seriação está entre os profissionais com 60 anos ou mais (1\%), e apenas $8 \%$ têm mais de 50 anos.

Com relação ao grau de escolaridade, observou-se que 73,6\% têm ensino médio, requisito mínimo para participar dos cursos AVSEC, e apenas 8,6\% declararam ter diploma de nível superior. O intervalo de 1 a 3 anos de tempo de serviço em AVSEC é predominante, seguido por profissionais com3 a 5 anos de experiência. No que concerne ao tempo de serviço no canal de inspeção, observou-se que os dados se assemelham ao tempo de serviço em AVSEC, uma vez que 35\% alegaram ter entre 1 a 3 anos de experiência laboral.

Considerando os aspectos relacionados à carga horária diária de trabalho no canal de inspeção, o dado majoritário corresponde ao período entre 4 a 6 horas (82\%). Tal carga horária está distribuída, por rotina de trabalho, em sua maioria, em turnos fixos, em $79 \%$ dos casos. No que tange à carga horária total de trabalho, incluindo outras atividades remuneradas para complementar a renda familiar, verificou-se que 88,6\%, trabalham entre 6 a 8 horas diárias. Apenas 3,6\% dos profissionais AVSEC declararam trabalhar mais de 11 horas diárias.

No que se refere ao salário, a maior frequência $(76,8 \%)$ encontra-se na faixa de $R \$ 900,00$ a $R \$ 1.199,00$. Do total de respondentes, 66,3\% participam do rodízio igualitário entre as funções AVSEC; $28 \%$ dos participantes exercem, na maior parte do tempo, uma função específica no canal de inspeção, com exceção do cargo de supervisor. Desse percentual, 21,4\% atuam predominantemente operando o equipamento de raios-X.

\section{Análise de Componentes Principais}

O estudo empreendido na validação do questionário originou um instrumento com 60 itens. Ao aplicar a técnica de $\mathrm{ACP}$, visando uma representação mais compacta dos dados, a eliminação de sobreposições e a escolha de formas mais representativas dos fatores e erros humanos, 46 itens foram agrupados em7dimensões estruturantes ou componentes principais (Tabela 3): (a) precisão procedimental e importância do trabalho; (b) entorno operacional e equívocos no canal de inspeção; (c) deficiências e simplificação dos procedimentos de 
segurança; (d) concentração e níveis de atenção; (e) fatores organizacionais; (f) aplicação e cumprimento dos procedimentos AVSEC; e (g) Aspectos relacionados à permanência na carreira AVSEC.

TABELA 3. Agrupamentos de componentes principais a partir dos itens do questionário

\begin{tabular}{|c|c|c|c|}
\hline CP & Título do CP & $\begin{array}{l}\text { \% da variância } \\
\text { critério Varimax }\end{array}$ & Questões \\
\hline 1 & $\begin{array}{l}\text { Precisão procedimental e importância do } \\
\text { trabalho }\end{array}$ & $8,28 \%$ & $21,22,23,24,29,30,31,32,43$ \\
\hline 2 & $\begin{array}{l}\text { Entorno operacional e equívocos no canal } \\
\text { de inspeção }\end{array}$ & $6,79 \%$ & $41,44,45,46,47,48,49,55,56,60$ \\
\hline 3 & $\begin{array}{l}\text { Deficiências e simplificação dos procedi- } \\
\text { mentos de segurança }\end{array}$ & $6,13 \%$ & $02,04,08,10,12,13,15,17,18$ \\
\hline 4 & Concentração e níveis de atenção & $6,12 \%$ & $19,25,26,27,28$ \\
\hline 5 & Fatores organizacionais & $6,05 \%$ & $33,38,42,51,52,53,54$ \\
\hline 6 & $\begin{array}{l}\text { Aplicação e cumprimento dos procedimen- } \\
\text { tos AVSEC }\end{array}$ & $4,52 \%$ & $01,07,09$ \\
\hline 7 & $\begin{array}{l}\text { Aspectos relacionados à permanência na } \\
\text { carreira AVSEC }\end{array}$ & $4,13 \%$ & 34,3537 \\
\hline
\end{tabular}

Em linhas gerais, tais itens demonstram os fatores e erros humanos apontados pela literatura da área, uma vez que os componentes principais 2, 5 e 7 incorporam os quatro eixos da representação esquemática instituída no DOC 9808 (OACI, 2002). Ademais, os componentes principais 1, 3, 4 e 6 englobam questões majoritariamente representadas no modelo de erros humanos delineado por Reason (2009). Entretanto, no caso do CP 1, três itens (31, 32 e 43) abrangem princípios fundamentais extraídos do DOC 9808 (OACI, 2002).

Para melhor compreensão sobre a representatividade de cada componente principal foram abordados os seguintes aspectos: os itens do questionário, o maior percentual obtido nas respostas dadas pelos respondentes ou a soma dos limites superiores ou inferiores (aquele que for mais significante em termos percentuais) e a justificativa para cada denominação alocada.

- CP 1: foi responsável por 8,28\% da variância total do instrumento, composto por 9 itens. Seus itens associam-se aos níveis de precisão e atenção na execução dos procedimentos AVSEC e com a percepção pessoal e social do exercício da atividade AVSEC, constante na Tabela 4.

TABELA 4. CP1: Precisão procedimental e importância do trabalho

\begin{tabular}{|c|c|c|}
\hline Itens & Escala & $\%$ \\
\hline $\begin{array}{l}\text { 21. Qual é o meu nível de atenção quando estou operando o equipamento de raios-X em condições } \\
\text { normais? }\end{array}$ & & $70 \%$ \\
\hline $\begin{array}{l}\text { 22. Qual é a precisão que tenho ao interpretar a coloração característica de um objeto projetado no } \\
\text { raios- X? }\end{array}$ & & $52 \%$ \\
\hline $\begin{array}{l}\text { 23. Qual é o meu nível de precisão na identificação de itens proibidos quando realizo inspeção com } \\
\text { detector manual de metais? }\end{array}$ & Total & $55 \%$ \\
\hline $\begin{array}{l}\text { 24. Qual é o meu nível de precisão na identificação de itens proibidos quando realizo busca pessoal } \\
\text { (revista)? }\end{array}$ & & $61 \%$ \\
\hline 29. Em que nível me sinto capaz para realizar busca pessoal (revista)? & & $55 \%$ \\
\hline $\begin{array}{l}\text { 30. Qual é o meu nível de conhecimento sobre os procedimentos de realização de busca pessoal } \\
\text { (revista)? }\end{array}$ & & $55 \%$ \\
\hline 31. O trabalho que executo é importante para mim. & & $55 \%$ \\
\hline 32. O trabalho que desempenho é importante para a sociedade. & $\begin{array}{l}\text { Concordo } \\
\text { totalmente }\end{array}$ & $78 \%$ \\
\hline 43. Os treinamentos AVSEC que eu recebo me tornam apto para o trabalho no canal de inspeção. & & $39 \%$ \\
\hline
\end{tabular}

- CP 2: concentraram-se os itens associados aos fatores geradores de falhas no canal de inspeção e às condições de trabalho. Tal componente alocou 10 itens, responsáveis por 6,79\% da variância total do instrumento, conforme representado na Tabela 5. 
TABELA 5. CP2: Entorno operacional e equívocos no canal de inspeção

Itens

41. A rotatividade de profissionais AVSEC que trabalham no canal de inspeção afeta diretamente o meu trabalho.

44. A maior parte dos equívocos que ocorrem no canal de inspeção é pelo fato de os profissionais não receberem uma formação adequada em AVSEC.

45. A maior parte dos equívocos que ocorrem no canal de inspeção é pelo fato de não ser disponibilizado um curso adequado de atualização AVSEC.

46. A maior parte dos equívocos que ocorrem no canal de inspeção é pelo fato de os profissionais não serem supervisionados corretamente pelo operador do aeródromo e/ou polícia responsável pela AVSEC no aeroporto.

47. A maior parte dos equívocos que ocorrem no canal de inspeção é consequência da grande movimentação de passageiros do aeroporto em que trabalho.

48. A maior parte dos equívocos que ocorrem no canal de inspeção é porque os gestores não passam instruções objetivas de trabalho.

49. A maior parte dos equívocos que ocorre no canal de inspeção é pelo fato de equipamentos em bom estado de conservação não estarem disponíveis.

55. O ruído no canal de inspeção afeta meu desempenho.

60. A proximidade da data do exame de certificação da ANAC afeta negativamente meu comportamento e desempenho no trabalho.

Discordo/discordo totalmente
$56 \%$

- CP 3: o componente implica negligências às responsabilidades das funções AVSEC e incidência de falhas operacionais. Composto por 9 itens, explicou 6,13\% da variância total do instrumento, de acordo com a Tabela 6.

TABELA 6: CP3: Deficiências e simplificação dos procedimentos de segurança

\begin{tabular}{|c|c|c|}
\hline Itens & Escala & $\%$ \\
\hline 2. Com que frequência observo deficiências na aplicação dos procedimentos de inspeção? & Às vezes & $51 \%$ \\
\hline $\begin{array}{l}\text { 4. Com que frequência minha atenção diminui no controle do fluxo devido à reposição da bandeja ou à necessi- } \\
\text { dade de ser cordial com os passageiros (entre outros)? }\end{array}$ & Nunca/às & $75 \%$ \\
\hline $\begin{array}{l}\text { 8. Com que frequência sou pressionado a simplificar os procedimentos de segurança para evitar filas, principal- } \\
\text { mente nos horários de grande movimentação de passageiros? }\end{array}$ & vezes & $53 \%$ \\
\hline
\end{tabular}

10. Com que frequência utilizo o celular quando estou operando o equipamento de raios- $X$ ?

12. Com que frequência me coloco no lugar do passageiro e simplifico o processo de inspeção de segurança AVSEC?

13. Com que frequência permito o acesso de um item à ARS, mesmo havendo dúvida durante a inspeção no equipamento de raios-X sobre a existência de objetos proibidos?

15. Quando estou responsável pela inspeção com o detector manual de metais, com que frequência libero o acesso do passageiro mesmo quando o detector insiste em acionar o alerta sonoro (quando o objeto parece não

17. Com base em minhas experiências, com que frequência realizo atividades não previstas nos procedimentos do posto de trabalho? 
- CP 4: abrange 5 itens conexos aos índices de concentração e atenção em serviço, envolvendo fatores externos ou internos ao profissional, e que explicou $6,12 \%$ da variância total do instrumento, como segue na Tabela 7.

TABELA 7.CP4: Concentração e níveis de atenção

\begin{tabular}{rrr}
\hline Itens & Escala & $\%$
\end{tabular}

19. No horário de grande movimentação de passageiros no canal de inspeção, qual é o nível da minha concentração no trabalho, mesmo com barulho excessivo?

Elevado/total $\quad 82 \%$

25. Qual é o meu nível de atenção no canal de inspeção quando estou estressado por causa da rotina de trabalho?

26. Qual o meu nível de atenção no equipamento de raios-X quando celebridades (artistas) acessam o canal de inspeção?

$59 \%$

27. Qual é o meu nível de atenção no trabalho quando estou estressado por motivos pessoais?

Total

28. Qual é o meu nível de atenção no trabalho quando tenho problemas familiares?

Elevado/total

$72 \%$

$68 \%$

- CP 5: composto por 7 itens, refere-se diretamente à cultura de segurança e à forma que os profissionais AVSEC e os recursos materiais são gerenciados e foi responsável por 6,05\% da variância total do instrumento, conforme a Tabela 8 .

TABELA 8. CP5: Fatores organizacionais

\begin{tabular}{|c|c|c|}
\hline Itens & Escala & $\%$ \\
\hline 33. O trabalho que executo é valorizado pela organização. & $\begin{array}{l}\text { Discordo/discordo } \\
\text { totalmente }\end{array}$ & $43 \%$ \\
\hline 38. O salário dos profissionais AVSEC me motiva a continuar nesta carreira. & & $65 \%$ \\
\hline 42. Os treinamentos em AVSEC são importantes para minha motivação no trabalho. & & $76 \%$ \\
\hline 51. Eu me sinto à vontade para relatar falhas ou equívocos que ocorrem no canal de inspeção. & & $45 \%$ \\
\hline $\begin{array}{l}\text { 52. São disponibilizados recursos materiais para a execução do meu trabalho, como detector manu- } \\
\text { al de metais, equipamentos de raios-X, esteira de processamento de bagagem, cadeira e monitores. }\end{array}$ & & $73 \%$ \\
\hline $\begin{array}{l}\text { 53. Os recursos materiais disponibilizados para a execução do meu trabalho estão em perfeitas } \\
\text { condições de uso, como detector manual de metais, equipamentos de raios-X, esteira de processa- } \\
\text { mento de bagagem, cadeira e monitores. }\end{array}$ & $\begin{array}{l}\text { Concordo/concordo } \\
\text { totalmente }\end{array}$ & $43 \%$ \\
\hline $\begin{array}{l}\text { 54. Sinto-me apoiado pela polícia responsável pela AVSEC no aeroporto ou pela administração } \\
\text { aeroportuária para desempenhar o meu trabalho no canal de inspeção. }\end{array}$ & & $38 \%$ \\
\hline
\end{tabular}

- CP 6: o componente está relacionado à exequibilidade e estrita observância dos conhecimentos e procedimentos AVSEC que devem ser implementados no canal de inspeção. Esse componente foi responsável por 4,52\% da variância total do instrumento, tendo sido composto por 3 itens, retratados na Tabela 9.

TABELA 9. CP6: Aplicação e cumprimento dos procedimentos AVSEC

Itens
$\begin{aligned} & \text { 1. Com que frequência é possível aplicar todos os conhecimentos dos cursos AVSEC, sem exce- } \\ & \text { ção, no canal de inspeção? }\end{aligned}$
$\begin{aligned} & \text { 7. Com que frequência é possível cumprir todos os procedimentos AVSEC quando há grande } \\ & \text { movimentação de passageiros? }\end{aligned} \quad$ Sempre/na maioria
$\begin{aligned} & \text { 9. Com que frequência é possível cumprir todos os procedimentos AVSEC quando há grande } \\ & \text { movimento de passageiros? }\end{aligned}$

- CP 7: o sétimo e último componente refere-se à continuidade empregatícia na ocupação laboral explorada neste estudo. Composto por 3itens, a percentagem da variância total do instrumento por ele explicada foi de $4,13 \%$, consoante a Tabela 10. 


\begin{tabular}{|c|c|c|}
\hline Itens & Escala & $\%$ \\
\hline 34. O trabalho que executo é temporário para mim. & \multirow{3}{*}{ Discordo/discordo totalmente } & $55 \%$ \\
\hline & & \\
\hline 35. Trabalho com AVSEC por falta de outras oportunidades de emprego. & & $73 \%$ \\
\hline 37. A permanência na carreira AVSEC é algo que desejo. & Concordo/concordo totalmente & $52 \%$ \\
\hline
\end{tabular}

Com base na hipótese de que a incidência de fatores e erros humanos no processo de inspeção impacta no desempenho dos profissionais que exercem funções em prol da segurança da aviação civil, elaborou-se a Tabela 11 com a classificação dos fatores e erros humanos. A coluna Predominância apresenta resultados advindos da aplicação dos questionários desta pesquisa, enquanto as demais abrangem dados extraídos da literatura.

A Tabela 11 retrata e correlaciona, à luz da literatura estudada, os seguintes aspectos: a forma de manifestação do fator/erro humano, a predominância de cada fator/erro humano (calculada a partir da quantidade de vezes que os respondentes optaram por um determinado item do questionário) e o tipo de fator e/ou erro humano relacionado à forma de manifestação. A partir desse critério, foi elaborada a classificação das formas de manifestação do fator/erro humano (Tabela 11).

Cabe mencionar que tais resultados não indicam que esses fatores ou erros humanos ocorrem ou incidem no sistema, mas que os percentuais atribuídos a determinados itens do questionário foram mais altos em relação aos demais, variando entre 27 a 65\% para os dez itens com maior predominância.

TABELA 11. Dez primeiros fatores/erros humanos que incidem nos canais de inspeção de segurança da aviação civil brasileira

\begin{tabular}{|c|c|c|c|c|}
\hline Classificação & Questão & Manifestação do fator/erro humano & Predominância & Tipo de fator/erro humano \\
\hline $1^{\circ}$ & 38 & $\begin{array}{l}\text { Salário: discordam/discordam totalmente que o salário } \\
\text { dos profissionais AVSEC os motivam a continuar nessa } \\
\text { carreira. }\end{array}$ & $65 \%$ & $\begin{array}{l}\text { Fator humano: DOC } 9808- \\
\text { retenção de pessoal }\end{array}$ \\
\hline $2^{\circ}$ & 56 & $\begin{array}{l}\text { Conforto térmico: concordam/concordam totalmente que a } \\
\text { temperatura no canal de inspeção afeta o desempenho. }\end{array}$ & $51 \%$ & $\begin{array}{l}\text { Fator humano: DOC } 9808- \\
\text { entorno operacional }\end{array}$ \\
\hline $3^{\circ}$ & 33 & $\begin{array}{l}\text { Valorização do trabalho: discordam/discordam totalmente } \\
\text { que o trabalho que executam é valorizado pela organiza- } \\
\text { ção. }\end{array}$ & $43 \%$ & $\begin{array}{l}\text { Fator humano: DOC } 9808- \\
\text { retenção de pessoal/cultura } \\
\text { de segurança }\end{array}$ \\
\hline $4^{\circ}$ & 53 & $\begin{array}{l}\text { Recursos: discordam/discordam totalmente que os recur- } \\
\text { sos materiais disponibilizados para a execução do traba- } \\
\text { lho estão em perfeitas condições de uso, como detector } \\
\text { manual de metais, equipamentos de raios-X, esteira de } \\
\text { processamento de bagagem, cadeira e monitores. }\end{array}$ & $38 \%$ & $\begin{array}{l}\text { Fator humano: DOC } 9808- \\
\text { entorno operacional }\end{array}$ \\
\hline $5^{\circ}$ & 51 & $\begin{array}{l}\text { Sistema de notificação: discordam/discordam totalmente } \\
\text { que se sentem à vontade para relatar falhas ou equívocos } \\
\text { que ocorrem no canal de inspeção. }\end{array}$ & $36 \%$ & $\begin{array}{l}\text { Fator humano: DOC } 9808- \\
\text { cultura de segurança }\end{array}$ \\
\hline $6^{\circ}$ & 54 & $\begin{array}{l}\text { Apoio: discordam/discordam totalmente que se sentem } \\
\text { apoiados pela polícia responsável pela AVSEC no aero- } \\
\text { porto ou pela administração aeroportuária para desempe- } \\
\text { nhar o trabalho no canal de inspeção. }\end{array}$ & $35 \%$ & $\begin{array}{l}\text { Fator humano: DOC } 9808- \\
\text { cultura de segurança/entorno } \\
\text { operacional }\end{array}$ \\
\hline \multirow[t]{2}{*}{$7^{\circ}$} & 41 & $\begin{array}{l}\text { Rotatividade: concordam/concordam totalmente que a ro- } \\
\text { tatividade de profissionais AVSEC que trabalham no canal } \\
\text { de inspeção afeta diretamente o trabalho. }\end{array}$ & $34 \%$ & $\begin{array}{l}\text { Fator humano: DOC } 9808- \\
\text { retenção de pessoal/seleção }\end{array}$ \\
\hline & 8 & $\begin{array}{l}\text { Simplificação: sempre e na maioria das vezes são pressio- } \\
\text { nados a simplificar os procedimentos de segurança para } \\
\text { evitar filas, principalmente nos horários de grande movi- } \\
\text { mentação de passageiros. }\end{array}$ & $34 \%$ & $\begin{array}{l}\text { Erro humano: excesso de } \\
\text { confiança/sobrecarga de in- } \\
\text { formação }\end{array}$ \\
\hline $8^{\circ}$ & 49 & $\begin{array}{l}\text { Equívocos associados aos equipamentos: concordam/ } \\
\text { concordam totalmente que a maior parte dos equívocos } \\
\text { que ocorrem no canal de inspeção é pelo fato de não ter } \\
\text { disponível equipamentos em bom estado de conservação. }\end{array}$ & $31 \%$ & $\begin{array}{l}\text { Fator humano: DOC } 9808- \\
\text { entorno operacional }\end{array}$ \\
\hline $9^{\circ}$ & 55 & $\begin{array}{l}\text { Ruído: concordam/concordam totalmente que o ruído no } \\
\text { canal de inspeção afeta o desempenho. }\end{array}$ & $30 \%$ & $\begin{array}{l}\text { Fator humano: DOC } 9808- \\
\text { entorno operacional }\end{array}$ \\
\hline
\end{tabular}


Por meio dessa classificação (Tabela 11), constatou-se que dos 10 principais elementos dos resultados, 9 são relativos a fatores humanos e apenas 1 é relacionado ao erro. Com efeito, a predominância dos fatores humanos nos achados da pesquisa é bastante relevante, considerando a problemática apresentada e a necessidade de manutenção dos seres humanos no trabalho realizado no canal de inspeção de segurança.

\section{DISCUSSÃO}

A área de security, especificamente no canal de inspeção de segurança da aviação civil brasileira, apresenta carência de estudos quanto à identificação, à quantificação, à causa e ao impacto de fatores e erros humanos. Nesse contexto, esta pesquisa demonstrou, por meio da ACP, a viabilidade de utilização do instrumento, bem como a validade do construto teórico-metodológico empregado para identificar os fatores ou erros humanos, e sua incidência global predominante em termos percentuais.

Por meio da análise, identificou-se que metade dos itens do questionário com maior predominância refere-se ao entorno operacional e aborda temas concernentes à valorização organizacional, à temperatura, a equipamentos, ao sistema de notificação, à supervisão, à rotatividade, à movimentação de passageiros e a ruído (Tabela 11). Essa constatação demonstra o quanto tais temas são representativos e, portanto, podem afetar o desempenho dos profissionais AVSEC. Para mitigação desses fatores e dos erros humanos mais incidentes, cabe salientar que estes reúnem questões cujas formas de solução são factíveis, objetivas e práticas. Observa-se, por exemplo, que a retenção de pessoal (salário recebido pelos profissionais AVSEC) poderia ser solucionada a partir do estabelecimento de políticas de progressão e promoção profissional que incluíssem o aumento salarial.

Já a questão do entorno operacional (conforto térmico) poderia ser mitigada, para fins de exemplificação, com a realização de uma pesquisa de opinião entre os profissionais AVSEC sobre o tema. A partir dos resultados obtidos e da identificação do possível desconforto, utilizando-se como parâmetro o previsto na ISO 7730, deveriam ser adotadas medidas capazes de proporcionar sua adequação à atividade realizada.

Um dado relevante é o fato de existir aproximadamente $8 \%$ dos respondentes com nenhuma e com menos de 1 mês de experiência como operador especializado em raios-X, e que o índice de tempo de serviço no canal de inspeção decresce a partir de 5 anos de experiência, o que pode representar o início do marco etário para o abandono da carreira AVSEC. Outra questão significativa é que a flexibilidade na escolha da rotina de trabalho pode ser considerada um atrativo à profissão AVSEC, uma vez que o nível salarial está na faixa de $\mathrm{R} \$ 678,00 \mathrm{a}$ $\mathrm{R} \$ 1.499,00(98,5 \%)^{2}$. Essa faixa salarial pode suscitar interesse em pessoas com formação na educação básica, pois, como visto anteriormente, quase $74 \%$ dos profissionais AVSEC apresentam apenas o ensino médio.

Considerando o grande volume de dados, a organização por meio da ACP buscou consolidar os objetivos deste estudo e serviu para validar sua hipótese: a incidência de fatores e erros humanos no canal de inspeção pode impactar no desempenho dos profissionais que exercem funções em prol da segurança da aviação civil e, consequentemente, no processo de inspeção de segurança.

Cabe salientar, contudo, que em um espaço de trabalho como o canal de inspeção, ainda que a equipe de trabalho seja composta por profissionais AVSEC motivados ou plenamente capacitados, a limitação humana não permite manter uma vigilância eficaz se forem ultrapassados limites curtos de atenção, conforme assegura Reason (2009). Tal limitação diminui a percepção e a identificação de ameaças ou vulnerabilidades no sistema se ultrapassados esses períodos curtos de atenção.

As formas mais comuns de transcendência a esses limites podem advir do trabalho residual, o qual pode ser representado pela atividade contínua, sem intervalo entre jornadas, substituições inesperadas ou ausência de profissionais capacitados para eventuais substituições, entre outros. Portanto, há necessidade de assegurar os rodízios das funções AVSEC no canal de inspeção, bem como de sinais automáticos que apoiam a decisão do profissional, como os alarmes dos pórticos e os detectores manuais de metais.

Os percentuais de erros decorrentes da captação externa constam, fundamentalmente, no CP 4. Logo, observa-se que o desenho do posto de trabalho e os recursos materiais disponíveis fazem a precisão procedimental

No período de elaboração do questionário e de sua aplicação, o salário mínimo no Brasil era de $\mathrm{R} \$ 678,00$. A partir do dia 01/01/2014, o valor nominal de referência passou a ser de $\mathrm{R} \$ 724,00$ (Guia Trabalhista, 2014). 
ser menos suscetível ao erro, conforme retratado na análise do $\mathrm{CP} 1$, em que pese os fatores internos ou externos ao indivíduo ainda exerçam bastante influência. Dessa forma, a supressão absoluta da incidência do fator ou erro humano se constitui como objetivo impraticável, pois o erro é parte inerente ao comportamento humano. Todavia, a supervisão e a cooperação entre os membros da equipe do canal de inspeção de segurança podem limitar o fator e o erro humano, bem como suas consequências.

Ao propor um estudo que reconhece a variabilidade no processo de inspeção de segurança por meio da investigação da incidência de fatores humanos que afetam o desempenho dos profissionais AVSEC, os fatores e erros humanos passam a ser reconhecidos como parte do sistema, e, portanto, podem ser suficientemente explorados para a melhoria do processo.

Considerando os índices obtidos sobre a percepção organizacional por parte dos respondentes, seja em decorrência do baixo salário recebido, seja da desvalorização do trabalho que desempenham, não obstante sua importância, além das questões que dizem respeito à temperatura e a ruído, fica claro que medidas devem ser adotadas pelos responsáveis para promover mudanças nesse cenário, e que sejam suficientes para provocar o decréscimo dos percentuais de fatores e erros humanos.

Esta pesquisa traz também uma contribuição social à classe profissional dos agentes de proteção de aviação civil, uma vez que identificou fatores e erros incidentes no processo de inspeção de segurança da aviação civil, os quais podem ser solucionados ou mitigados por medidas tangíveis, exequíveis, objetivas e práticas. Com a implementação de medidas práticas, pressupõe-se que ocorra a valorização contínua desses profissionais, fundamentais na manutenção da segurança nacional e internacional.

Sendo o elemento humano parte indissociável do processo de inspeção, até o presente momento, o fator e o erro em potencial, o anseio por extingui-los é inexequível. Dessa forma, observa-se que o erro e o fator humano constituem-se como parte inerente da condição humana, ainda que se disponha de profissionais que estejam qualificados no rigor normativo e certificados para o exercício de sua função.

No entanto, cabe salientar que a incidência do fator e do erro humano em sistemas complexos é tolerável, dada a estrutura do sistema de defesa em profundidade e a utilização de recursos tecnológicos que apoiam a atuação profissional. Ademais, o convívio com esse fator e os possíveis erros é inevitável ante a necessidade de executar tarefas complexas e de alto risco, nas quais o ser humano é um elemento indispensável.

As limitações deste estudo se relacionaram às restrições financeiras, aliadas à carência de instrumentos destinados à avaliação da incidência de fatores humanos no processo de inspeção de segurança, e ao fato de ter sido empregado apenas no contexto brasileiro. No caso de adoção do instrumento da pesquisa por outros países interessados, recomenda-se que sejam despendidos esforços para sua normatização na cultura correspondente, não obstante tenha sido parcialmente baseado no manual emitido pela OACI sobre a matéria, a qual fornece orientações aos seus países signatários.

Em conclusão, os resultados advindos desta pesquisa constituem-se um esforço pioneiro para a sua concretização como instrumento de trabalho e como fonte de informação para possíveis intervenções no contexto laboral dos profissionais AVSEC, tanto pelos operadores aéreos, aeroportuários e pela própria agência reguladora do setor. Sendo a segurança o objetivo final de todos aqueles que se dedicam à aviação, é essencial assegurar um nível apropriado de conhecimento em matéria de fatores e erros humanos em toda a indústria, com vistas a fornecer subsídios mínimos necessários para seu controle e mitigação.

\section{REFERÊNCIAS}

Abrahão, J., Sznelwar, L. I., Silvino, A., Sarmet, M., Pinho, D. (2009). Introdução à ergonomia: Da prática à teoria. São Paulo: Blucher.

Agência Nacional de Aviação Civil. (2013). AVSEC habilitados: 2013. Brasília: ANAC. Recuperado de http://www2.anac.gov.br/ avsec/

Agência Nacional de Aviação Civil \& Empresa Brasileira de Infraestrutura Aeroportuária. (2014). Estudo canais de inspeção. Brasília: ANAC.

Airports Council International. (2012). World airport traffic report. Recuperado de http://www.aci.aero/Publications/FullPublications-Listing/ACI-ANNUAL-World-Airport-Traffic-Report-WATR

Amores, C. C., \& Fernández, I. L. (2012). Descubrir la seguridad aeroportuária. Madrid: Centro de Documentaciones y Publicaciones de Aena - Aeropuertos Españoles e Navegación Aérea. 
Bolfarine, H., \& Bussab, W. O. (2000). Elementos de amostragem: Versão preliminar. São Paulo: Instituto de Matemática e Estatística da Universidade de São Paulo.

Guia Trabalhista. (2014). Tabela dos valores nominais do salário mínimo. Recuperado de: //www.guiatrabalhista.com.br/guia/ salario_minimo.htm

Lei 7.565, de 19 de dezembro de 1986 (1986, 19 de dezembro). Dispõe sobre o código brasileiro de aeronáutica. Recuperado de http://www.planalto.gov.br/ccivil_03/leis/L7565.htm

Organización de Aviación Civil Internacional. (1998). DOC 9683: Manual de instrucción sobre factores humanos (1a ed.). Montreal: OACI.

Organización de Aviación Civil Internacional. (2002). DOC 9808: Los factores humanos em las operaciones de seguridad de la aviación civil. Montreal: OACI.

Reason, J. (1990). Human error. Cambridge: Cambridge University Press.

Reason, J. (2009). El error humano. Madrid: Modus Laborandi.

Strauch, Barry. (2002) Investigating human error: Incidents, accidents and complex systems. England: Ashgate.

Tadeu, H. F. B. (2010). Logística aeroportuária: Análises setoriais e o modelo de cidades-aeroportos. São Paulo: Cengage Learning. 